\title{
Performance Evaluation and Pounding Effects between KPFT Building Alternative Design for SGLC Building
}

\author{
Rusgiyanto ${ }^{1, *}$ \\ 'Zamil Engineering Consultant Company, Yogyakarta, INDONESIA \\ *Corresponding authors: rusgiyanto.civil@gmail.com
}

SUBMITTED 21 November 2018 REVISED 25 December 2018 ACCEPTED 11 January 2019

\begin{abstract}
Main Office building of the Faculty of Engineering (KPFT) is one of the buildings located within the complex of the Faculty of Engineering, Universitas Gadjah Mada. There is a plan to build a new building adjacent to the KPFT building. The design can interact simultaneously in support of earthquake so that the pounding effect can occur. The pounding effect due to earthquake loads is to improve the quality of KPFT building. This study applies numerical study to determine the effect of adding new structures around the old structure. This research uses 3 structure models, i.e. KPFT building without a wall (SKTD), the new Smart and Green Learning Center (SGLC) structure (SB), and the composite building (SG). This research uses linear time history analysis. There are 3 earthquake records including Superstition Hills-02, Darfield New Zealand, and El Mayor-Cucapah. The results shows story drift from the KPFT building (SKTD model) is reduced after the adjacent building has occurred. The performance level for SKTD models is Life Safety (LS), whereas the performance level for KPFT building after combining with the new structure is Operational (OP). The KPFT building after combining with new structure has a better performance level due to its drift ratio.
\end{abstract}

KEYWORDS Pounding effect; performance level; time history

(c) The Author(s) 2018. This article is distributed under a Creative Commons Attribution-Share Alike 4.0 International license

\section{INTRODUCTION}

The KPFT Building (Main Office building of Faculty of Engineering) is one of the buildings in the Faculty of Engineering complex, Gadjah Mada University. This building functioned as an educational building and an administration office of the Faculty of Engineering. In 2006 this building supported the earthquake load and resulted in several cracks in the building. After that KPFT building began to be investigated by several researchers. The results of these studies stated that the building was still in a safe condition but did not meet the requirements as a building with a risk category IV.

In 2016 there was a plan to build a new building in the area where the KPFT building was built, with the design still maintaining the existence of the KPFT building. The KPFT building is adjacent to a new building. The construction of a new building adjacent to the KPFT building is to improve the quality of the KPFT building. The construction of this new building must be designed to meet the requirements contained in SNI 1726-2012 for buildings with risk categories IV (BSN, 2012). In order to fulfill the objectives of improving the quality of the KPFT building, this new building must be able to interact directly with the KPFT building. Both of these buildings must be able to interact, especially when supporting earthquake loads.

\section{RESEARCH OF KPFT BUILDING}

Sandra (2007) re-analyzed the KPFT building using the 2002 earthquake regulations. The analysis carried out was an earthquake analysis of the response spectrum of the KPFT building model after the Yogyakarta earthquake. The results of the research revealed that the width of cracks in beams and columns was smaller than the crack width that is permitted on SNI 03-28472002 (BSN, 2002). The strength of beams and columns still meets the bending and axial requirements, while the beam shear strength was smaller than the shear force that occurs.

Jamal (2009) research on the characteristics of the KPFT building. The study using a seismometer and compared it with numerical modeling. The results of this study found that the natural frequency of NS direction is $1.9043 \mathrm{~Hz}$ (0.5251 seconds) and in the EW 
direction is $1.8555 \mathrm{~Hz}$ (0.5389 seconds). Maximum acceleration that can be supported is less than the base rock acceleration where the KPFT building was built.

Akhsan (2014) evaluates the KPFT building by conducting Rapid Visual Screening based on FEMA 154 (2002) and conducting a more detailed evaluation based on FEMA 310 (1998). The results of the research are structured level performance, according to ATC- 40 based on the storey drift for the roof and $3^{\text {rd }}$ floor Immediate Occupancy, $2^{\text {nd }}$ floor Life Safety, and $1^{\text {st }}$ floor Damage Control. According to FEMA-356 and FEMA 302 based on the storey drift for roofs and 3rd floor Immediate Occupancy, $2^{\text {nd }}$ floor Collapse, and $1^{\text {st }}$ floor Life Safety (ASCE, 2000).

\section{POUNDING EFFECT}

Maison and Kasai (1990) the building under study is a 15 -storey building with a steel frame structure and nearby buildings the concrete remains lower than the reviewed building. In this study the building under review experienced pounding with the surrounding building on the $1^{\text {st }}$ floor of the building. Pounding produces drift, shear forces and moments on the floors above the location of the pounding are greater than the building that is not experiencing pounding.

Rojas (2012) conducted a pounding study of 18-Story Building during Recorded Earthquake. The building used as a case study is an 18-storey steel frame office building which is adjacent to a 5-storey high-rise parking building with a distance between the two buildings of $50.8 \mathrm{~mm}$. In this study, it was found that the effect of the pounding did not only affect the changes in structural behavior and shear forces that occur on each floor. On the floor that is in contact with the surrounding structure gives a smaller shear force than the shear force on the floors below it. However, the value of the Demand Capacity Ratio (DCR) column on the floor that experiences contact is greater than the floor below and the floor above it.

\section{RESEARCH METHOD}

This research is a numerical study to determine the effect of adding new structures around old buildings. The parameters observed in this study are the maximum displacement of the roof, story drift, the shear force that occurs, and the level performance of the structure.

\subsection{SGLC Building Description}

The construction of a Smart and Green Learning Center (SGLC) is designed adjacent to the Main Office building of the Faculty of Engineering (KPFT), which has already been established. The building floor plan as shown in Figure 1and the design of the SGLC building as shown in Figure 2.

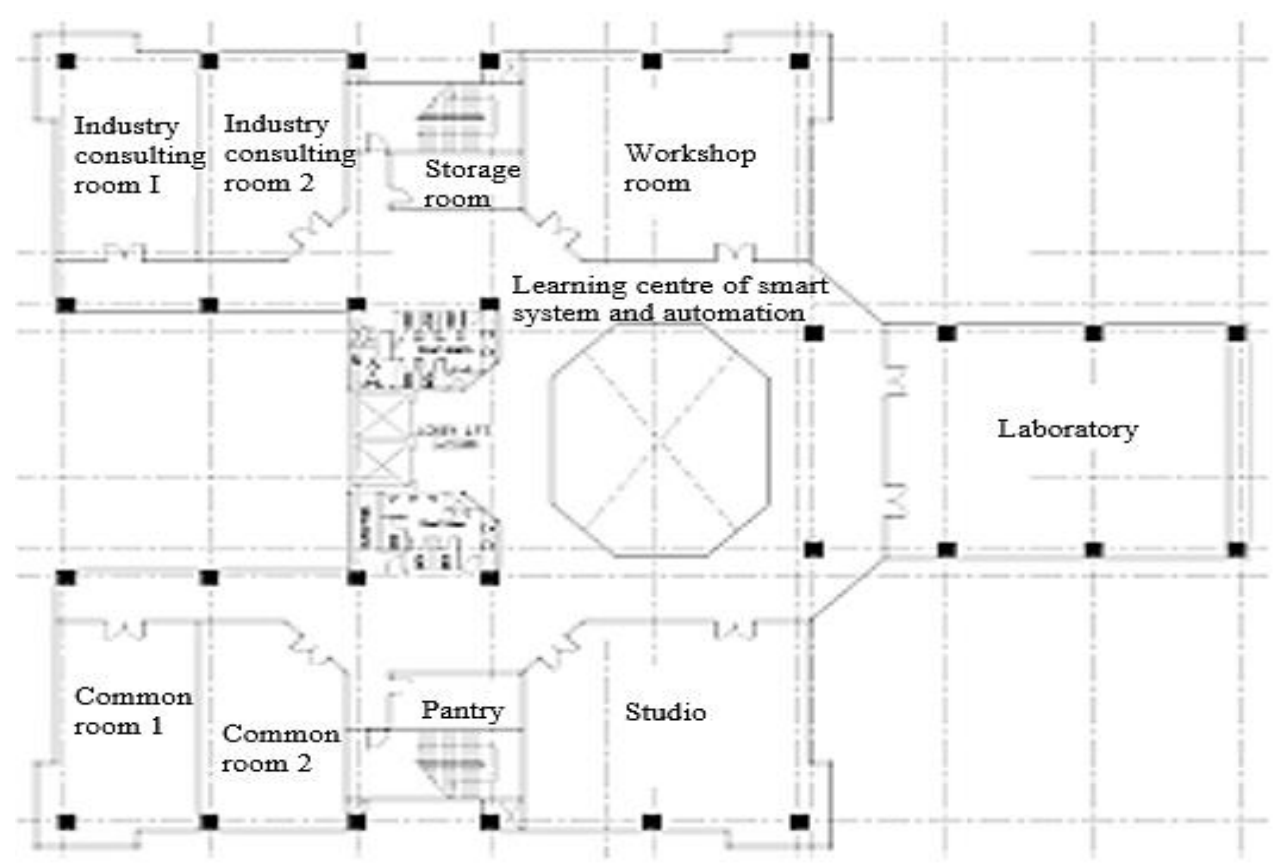

Figure 1. Typical floor plans for SGLC buildings. 


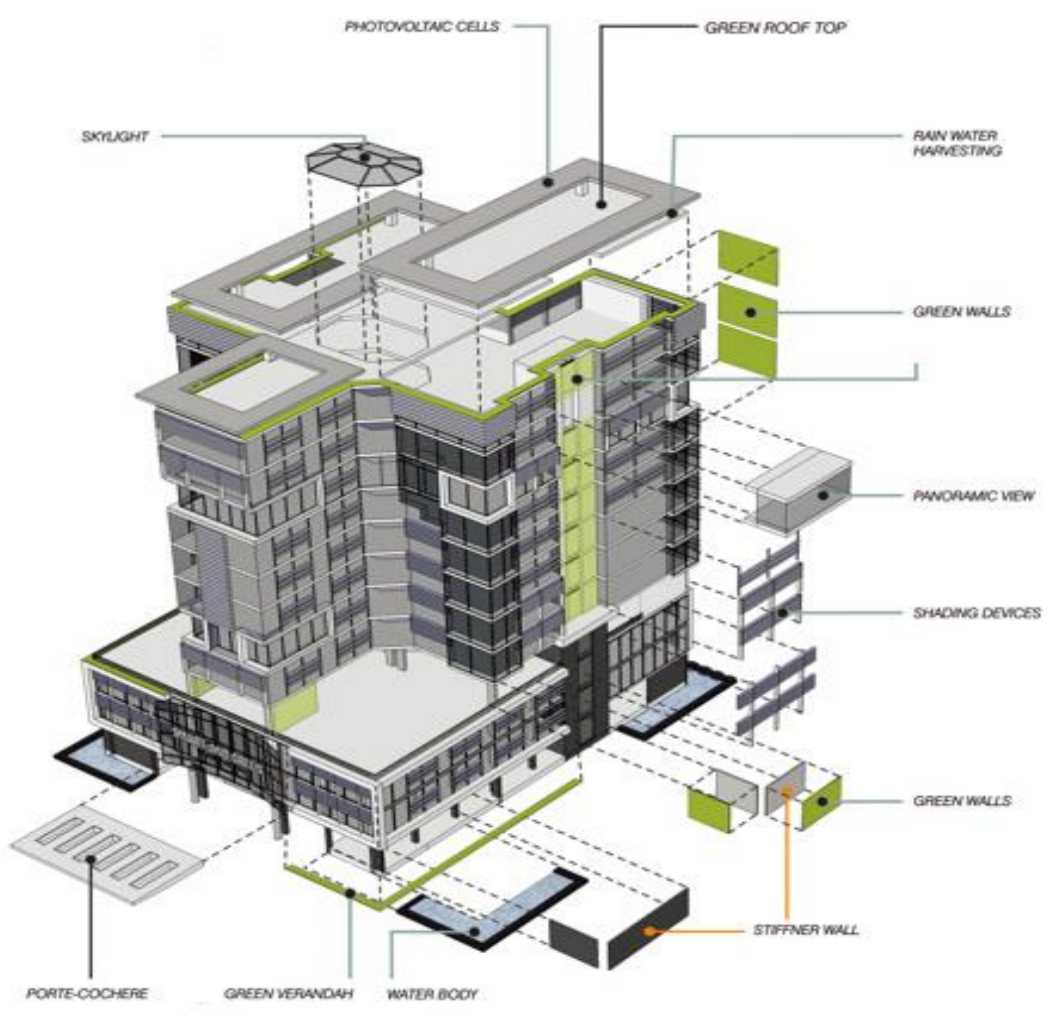

Figure 2. Design of SGLC building.

\subsection{Structure Model}

In this study 3 modeling pieces were made; the structure was modeled as a 3D model. The model structure is fixed on the pile cap section, while the shallow foundation is modeled as joint support. The three modeling is made:

a) KPFT building without a wall (see Figure 3)

b) New structure of the SGLC building (see Figure 4)

c) The composite building of SGLC building as can be seen in Figure 5 consists of:

- KPFT building without a wall (SG)

- The new structure of SGLC building (SB)

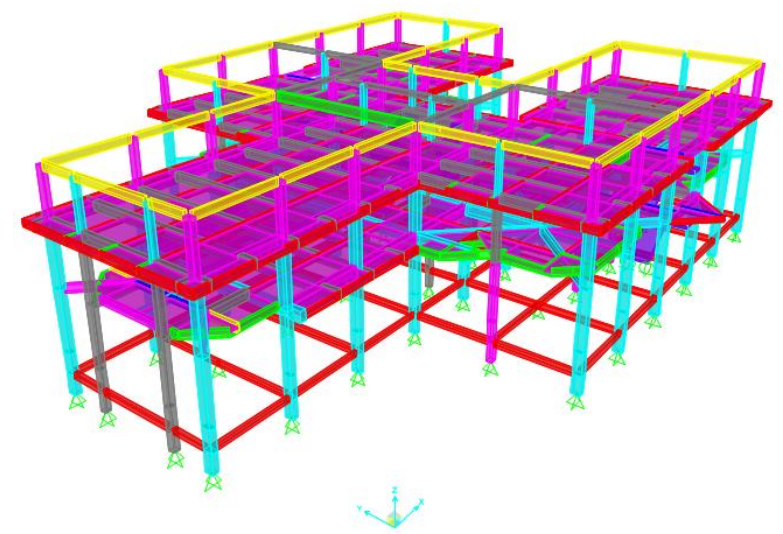

Figure 3. KPFT building without wall model (SKTD).

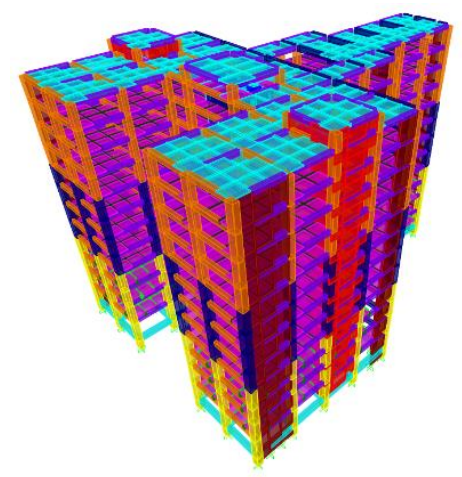

Figure 4. Alternative structure design SGLC model (SB).

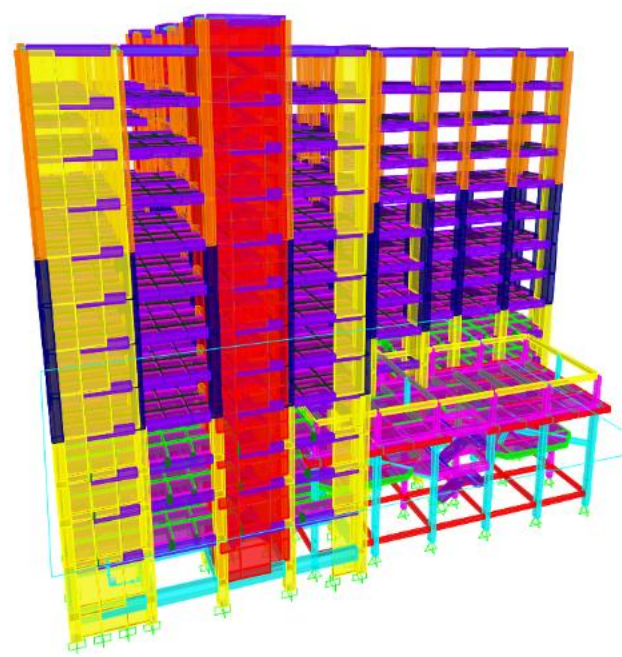

Figure 5. Composite building model (SG). 


\subsection{Earthquake Loads}

Researchers use 3 earthquake recording data that have spectrum characteristics and responses that approach the characteristics of the Yogyakarta earthquake and Yogyakarta spectrum response. Spectrum response values is shown in Figure 6.

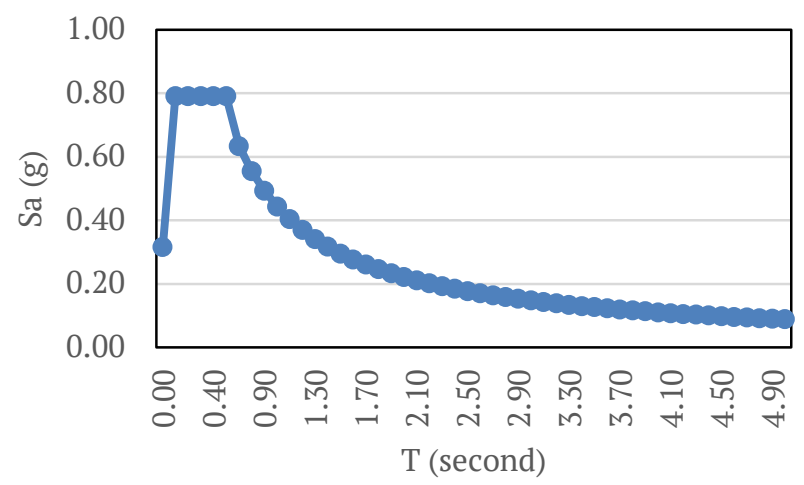

Figure 6 . The target of spectrum response.

Earthquake records from each earthquake (Table 1) as shown from Figure 7 to Figure 9. Figure 10 shows the response spectrum of each earthquake record compared to the target response spectrum in the area where the building was built.

Table 1. Earthquake record

\begin{tabular}{llcl}
\hline No & Name & Year & Station \\
\hline 1 & Superstition Hills-02 & 1987 & El Centro Imp. \\
2 & Darfield New Zealand & 2010 & DFHS \\
3 & El Mayor-Cucapah & 2010 & El Centro Array \#12 \\
\hline
\end{tabular}

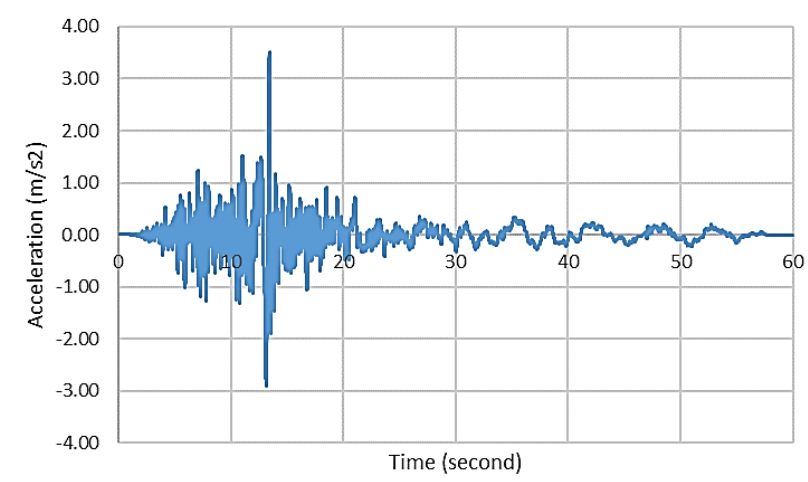

Figure 7. Superstition Hills-02 record.

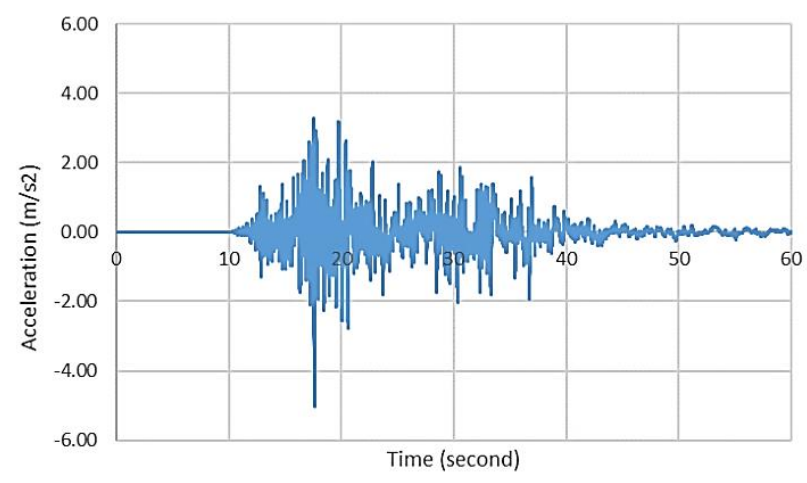

Figure 8. Darfield New Zealand record.

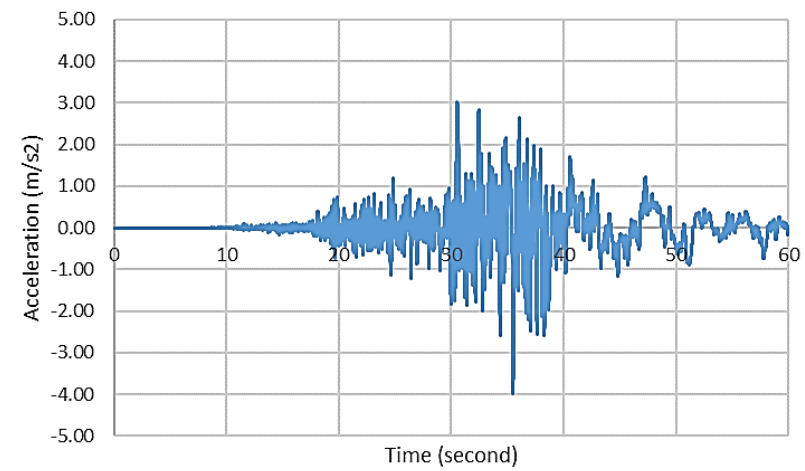

Figure 9. El-Mayor Cucapah record.

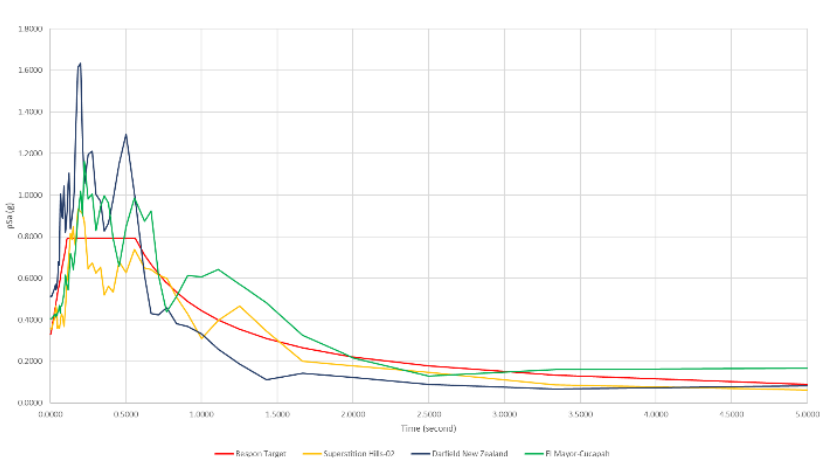

Figure 10. Spectrum response each earthquake record.

\subsection{Elastomer Bearing Calculation}

The elastomer bearing dimensions that will be used is based on the amount of force that occurs at the points to be given the elastomer bearing. At the points to be given the elastomer is modeled as a linking gap that behaves linearly and is carried out by seismic load so that the greatest compressive force of the earthquake loads is obtained. The maximum force acting on the link is $241.46 \mathrm{kN}$. 
The force then used to find the appropriate dimensions in the product catalog from the elastomer bearing manufacturers. So that the elastomer bearing is used with dimensions of $150 \times 200 \times 16 \mathrm{~mm}$. Material data as shown in Table 2. This elastomer has a maximum carrying capacity of $300 \mathrm{kN}$.

Table 2. Elastomer bearing datasheet

\begin{tabular}{ll}
\hline Parameter & Value \\
\hline Width & $150 \mathrm{~mm}$ \\
Length & $200 \mathrm{~mm}$ \\
Thickness & $16 \mathrm{~mm}$ \\
Cover thickness & $2.5 \mathrm{~mm}$ \\
The thickness of the internal layer & $5 \mathrm{~mm}$ \\
Number of layers & 1 piece \\
The thickness of steel plate & $3 \mathrm{~mm}$ \\
Number of platelayers & 2 pieces \\
Quality steel plate & $360 \mathrm{MPa}$ \\
Modulus of elasticity & $2120 \mathrm{MPa}$ \\
Vertical stiffness & $3,975,000 \mathrm{~N} / \mathrm{mm}$ \\
\hline
\end{tabular}

\section{RESULTS AND DISCUSSION}

\subsection{Shear Force}

\subsubsection{KPFT building}

Shear forces on KPFT structure as shown in Figure 11. The $1^{\text {st }}$ and $2^{\text {nd }}$ floors the shear force are almost the same because the wall elements are not modeled and only the wall weight is modeled so that the stiffness of $1^{\text {st }}$ and $2^{\text {nd }}$ floor are relatively the same.

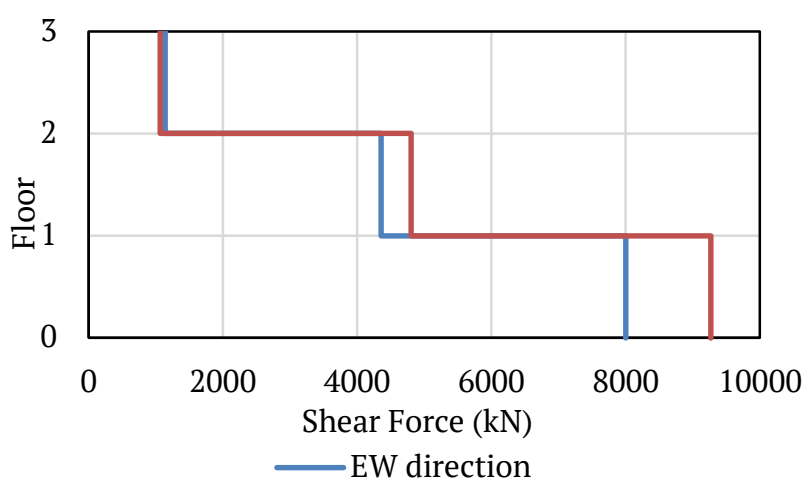

Figure 11. Shear force SKTD.

\subsubsection{New structure SGLC (SB)}

The biggest shear force occurs on the $4^{\text {th }}$ floor, which on this floor is the transitional floor of the floor that is not fully covered by the floor plate to the part of the building where the floor is almost completely covered by floor slabs. Shear force SB can be seen in Figure 12 .

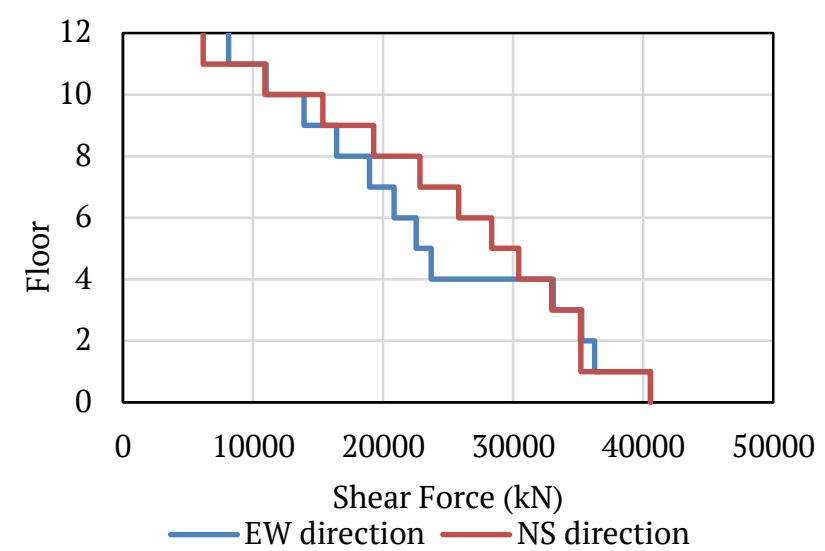

Figure 12. Shear force SB.

\subsubsection{Composite structure of SGLC (SG)}

In the SKG structure, as shown in Figure 13, the biggest shear force occurs on the $1^{\text {st }}$ floor. This floor is functioning as an office area while on the $2^{\text {nd }}$ and $3^{\text {rd }}$ floors it functions as a lecture area. The difference in function of this space causes a difference in the shear force on each floor. The biggest shear force of SBG structure (Figure 14) occurs on the $4^{\text {th }}$ floor because this floor is a transitional floor which is not fully covered by the floor plate to the floor that covering floor plate almost the entire floor.

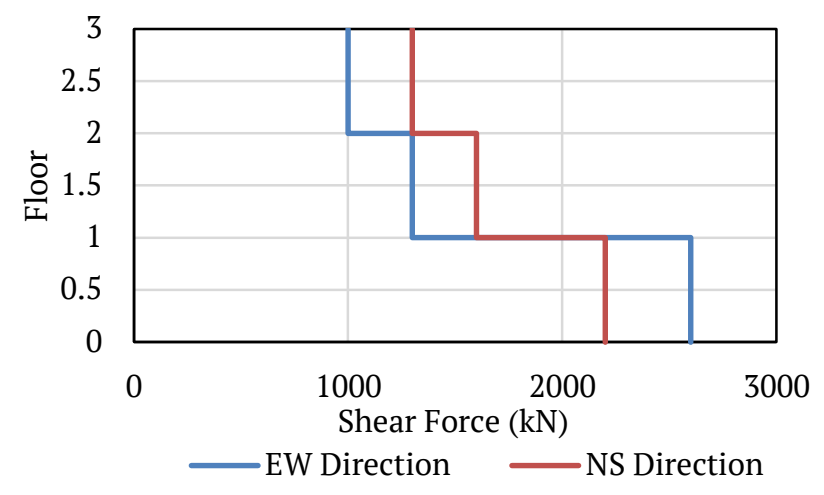

Figure 13. Shear force SKG.

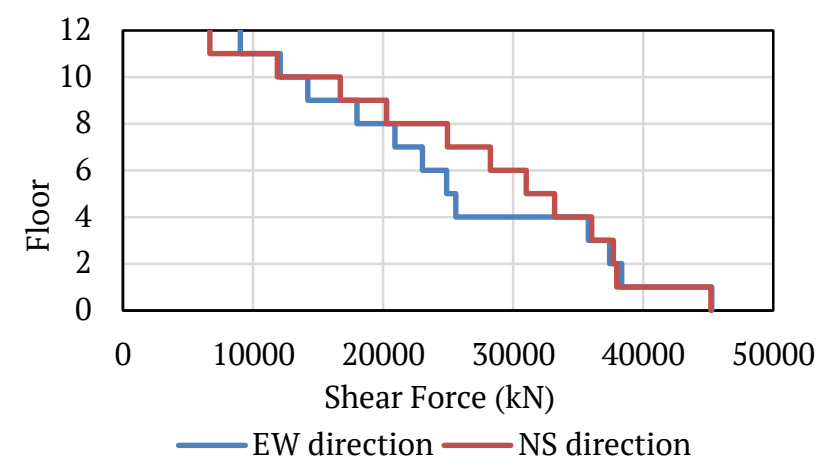

Figure 14. Shear force SBG. 


\subsubsection{Comparison of shear force structures before and after pounding}

The SKTD shear force compared to SKG shows that the SKTD shear force is greater than the SKG shear force, especially the shear force on the $1^{\text {st }}$ floor. This is because the shear force that occurs in the SKG will largely be supported by the SBG structure. Whereas the SB shear force when compared to SBG the shear force that occurs in SBG will be greater than the SB shear force. This is a reaction from the SBG structure because there is an SKG structure nearby. The comparison of shear force for EW and NS direction are shown from Figure 15 to Figure 18.

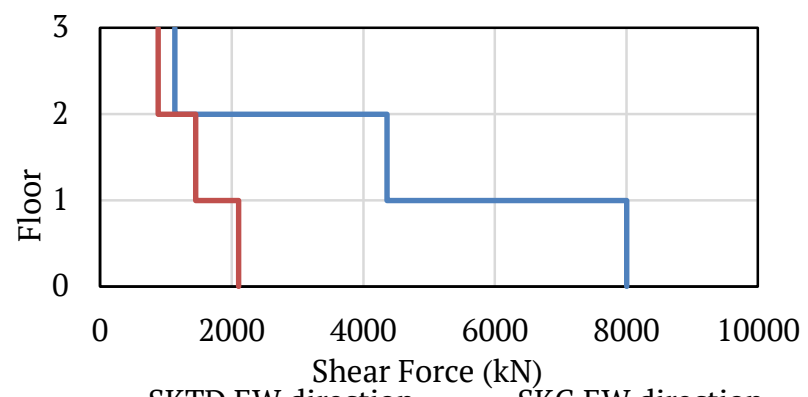

Figure 15. Comparison of SKTD and SKG shear force on EW direction.

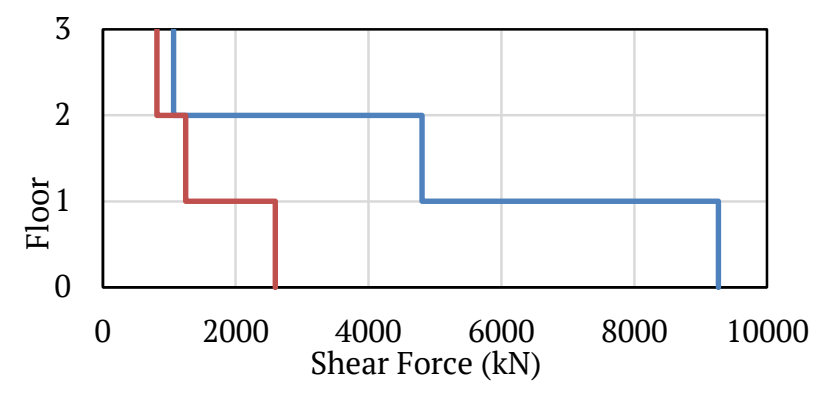

SKTD NS direction —SKG NS direction

Figure 16. Comparison of SKTD and SKG shear force on NS direction.

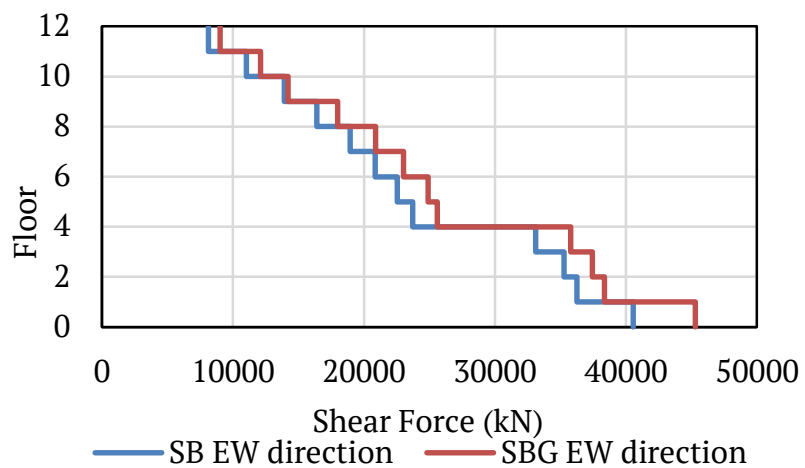

Figure 17. Comparison of SB and SBG shear force on EW direction.

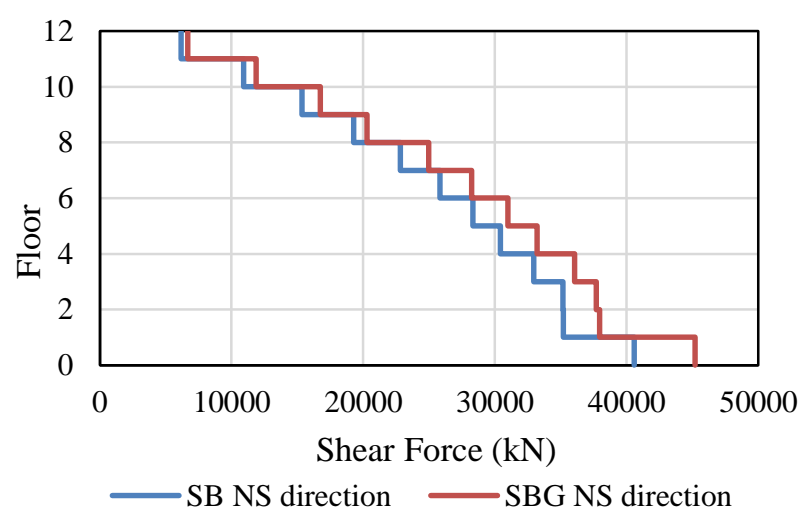

Figure 18. Comparison of SB and SBG shear force on NS direction.

\subsection{Floor Deflection}

\subsubsection{KPFT building}

The largest floor deflection of SKTD model for EW direction is $86.67 \mathrm{~mm}$ and NS direction is $94.00 \mathrm{~mm}$. Deflection of each floor during the largest deflection on the top floor as shown in Figure 19 and Figure 20.

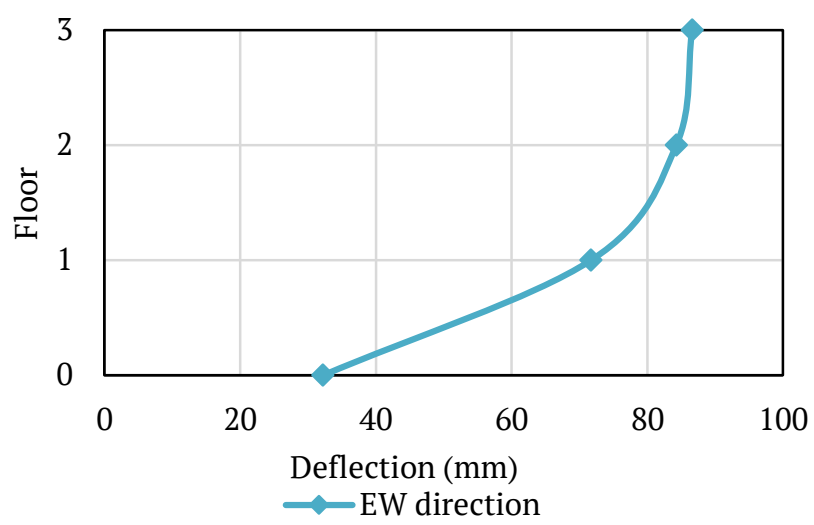

Figure 19. Floor deflection SKTD model for EW direction, ElMayor earthquake.

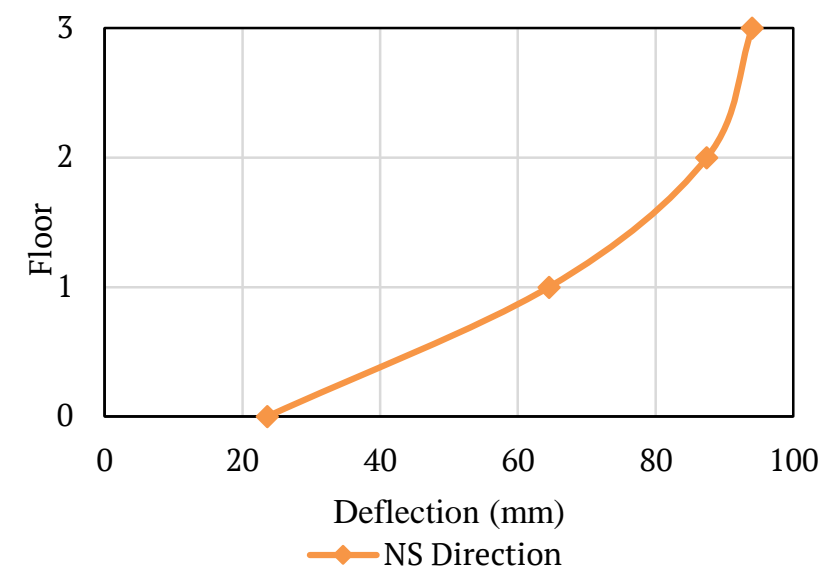

Figure 20. Floor deflection SKTD model for NS direction, ElMayor earthquake. 


\subsubsection{New structure SGLC (SB)}

The largest floor deflection of SB model for EW direction is $97.23 \mathrm{~mm}$ and NS direction is $89.95 \mathrm{~mm}$. Deflection of each floor during the largest deflection on the top floor as shown in Figure 21 and Figure 22.

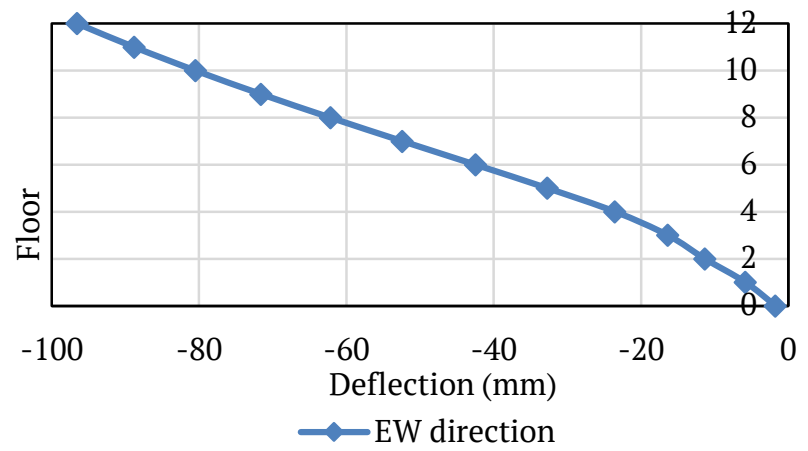

Figure 21. Floor deflection SB model for EW direction, ElMayor earthquake.

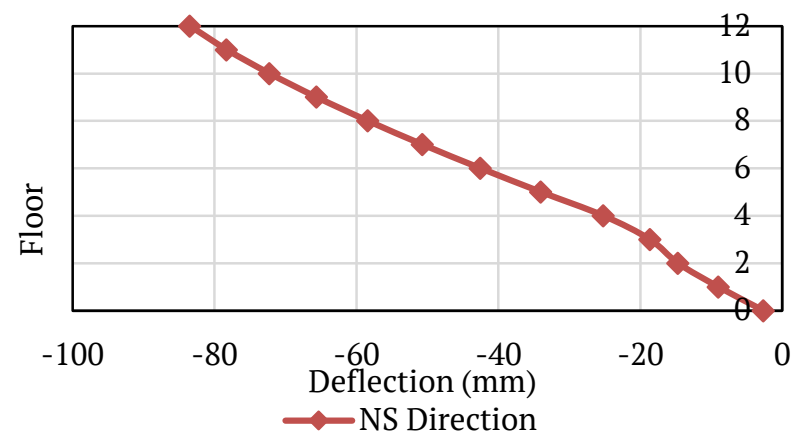

Figure 22. Floor deflection SB model for NS direction, ElMayor earthquake.

\subsubsection{Composite structure of SGLC (SG)}

The results of the analysis show that the highest peak floor deflection of the US direction SKG structure is $15.89 \mathrm{~mm}$ while the BT direction is $18.29 \mathrm{~mm}$. In the structure of the peak floor deflection SBG that occurs in the BT direction of $95.67 \mathrm{~mm}$ while the US direction is $83.43 \mathrm{~mm}$. Deflection of each floor as shown in from Figure 23 to Figure 26.

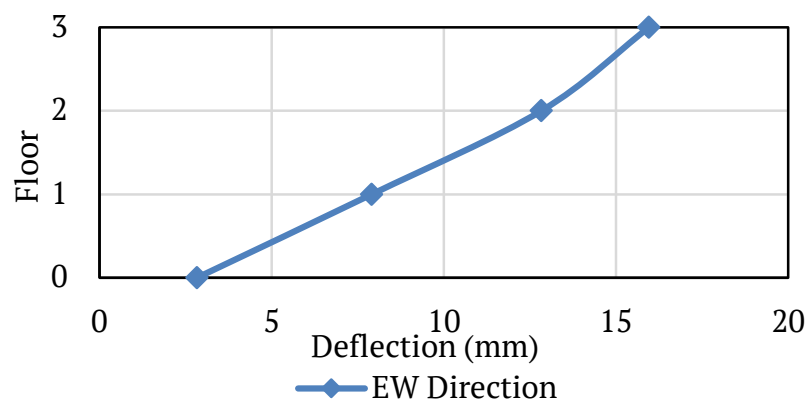

Figure 23. Floor deflection SKG model for EW direction, ElMayor earthquake.

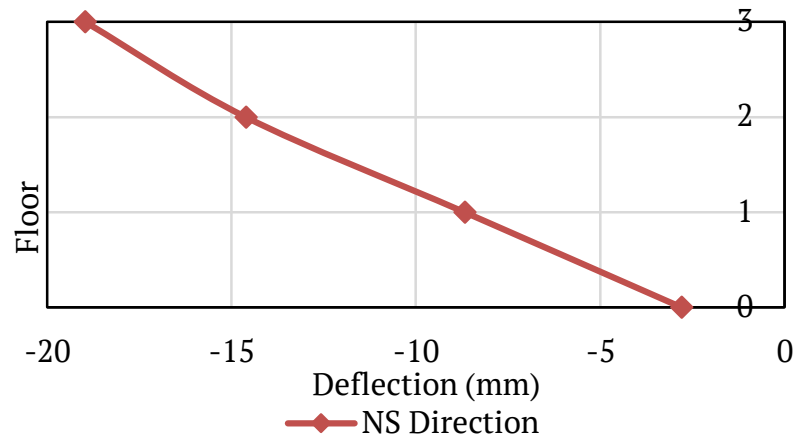

Figure 24. Floor defection SKG model for NS direction, El-Mayor earthquake.

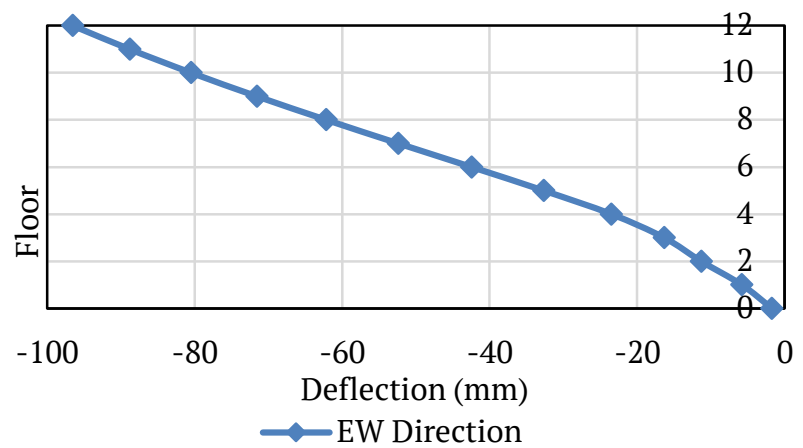

Figure 25. Floor deflection SBG model for EW direction, El-Mayor earthquake.

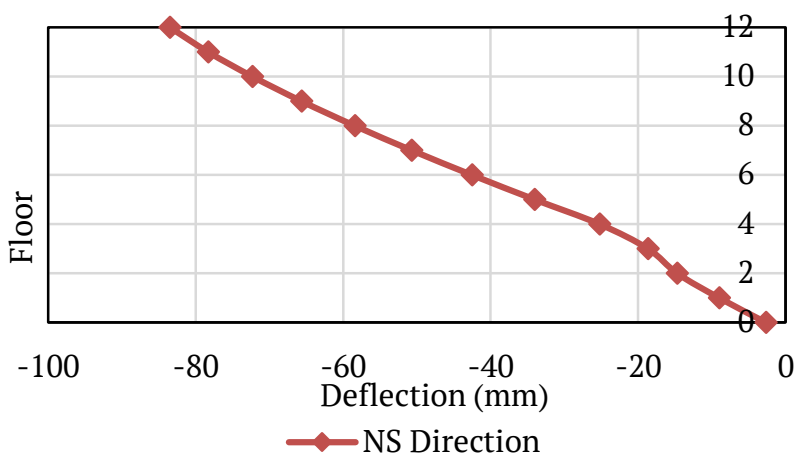

Figure 26. Floor deflection SBG model for NS direction, El-Mayor earthquake.

\subsubsection{Comparison of floor deflection structures before and after pounding}

Floor deflection over SKTD structure large compared to the floor deflection that occurs in the SKG structure. The deflection of the structure of the SB structure is greater than the deflection in the SBG structure. A deflection that occurs on $1^{\text {st }} 5^{\text {th }}$ floor of SB and SBG structures has a very small difference. Greater deflection difference occurs on the $5^{\text {th }}$ to $12^{\text {th }}$ floors. Comparison of floor deflection for EW and NS direction can be seen from Figure 27 to Figure 30 . 


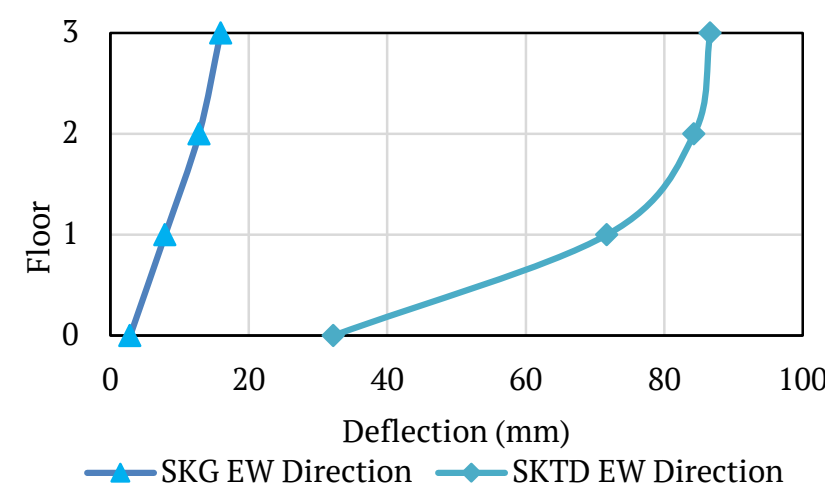

Figure 27. Comparison of SKTD and SKG floor deflection on EW direction.

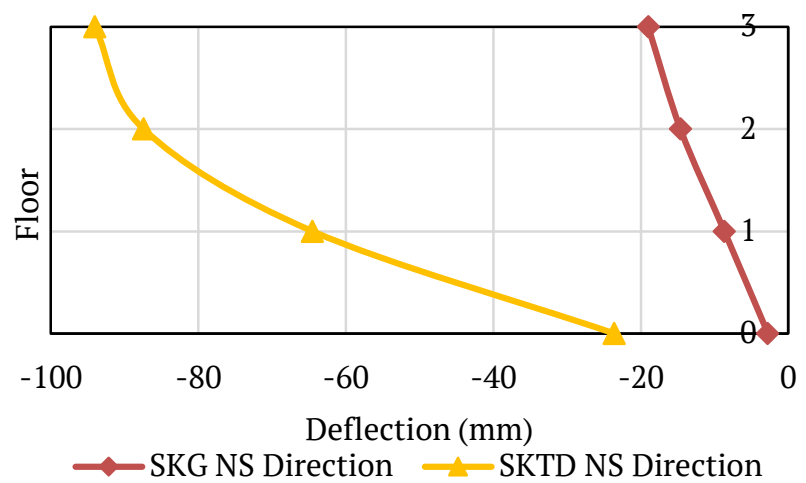

Figure 28. Comparison of SKTD and SKG floor deflection on NS direction.

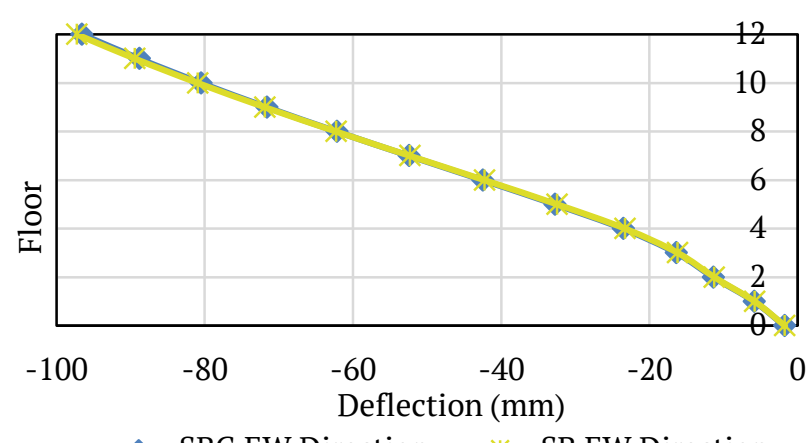

$\leadsto$ SBG EW Direction $\because$ SB EW Direction

Figure 29. Comparison of SB and SBG floor deflection on EW direction.

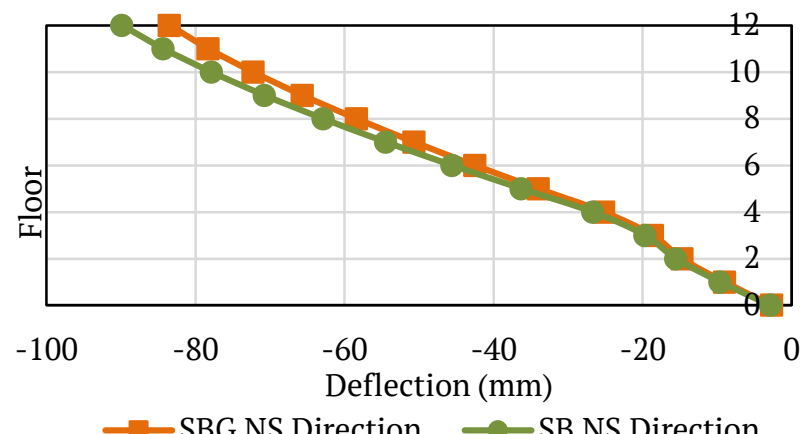

Figure 30. Comparison of SB and SBG floor deflection on NS direction.

\subsection{Drift Ratio}

\subsubsection{KPFT building}

The maximum drift ratio of SKTD model is $2.90 \%$ for EW direction and $3.04 \%$ for NS direction. The results of the drift ratio are more than $1 \%$ indicate that the SKTD structure does not meet the requirements as a building with a risk category IV in accordance with SNI 1726-2012 (BSN, 2012).

Figure 31 shows the performance level of SKTD model in the EW direction of the $1^{\text {st }}$ floor is Collapse Prevention (CP), the $2^{\text {nd }}$ floor is Immediate Occupancy (IO), and the $3^{\text {rd }}$ floor is Operational $(\mathrm{OP})$. While Figure 32 shows the performance level of SKTD model in the NS direction of the $1^{\text {st }}$ floor is Collapse Prevention (CP), the $2^{\text {nd }}$ floor is Life Safety (LS) and the $3^{\text {rd }}$ floor is Operational (OP).

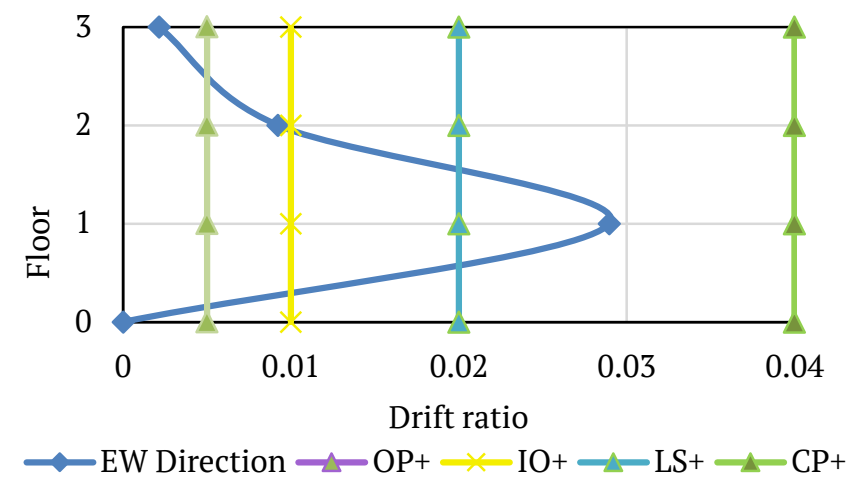

Figure 31. Drift ratio SKTD model in EW direction, El-Mayor earthquake.

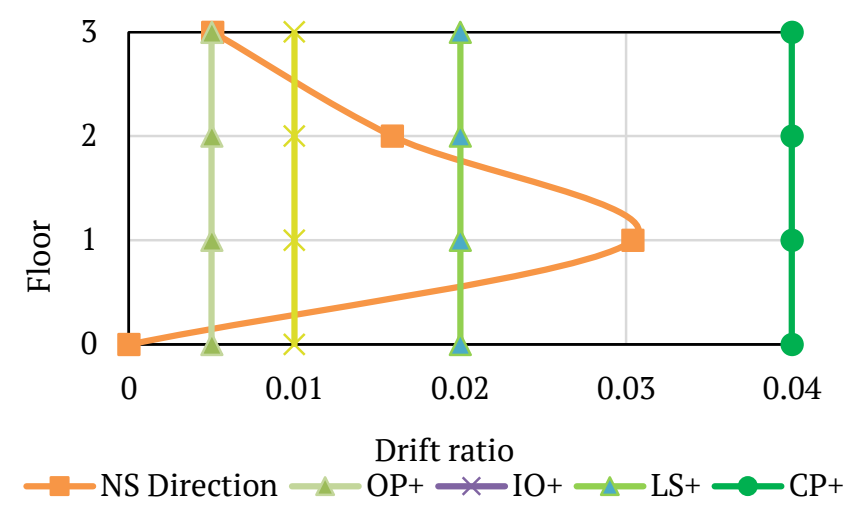

Figure 32. Drift ratio SKTD model in NS direction, El-Mayor earthquake.

\subsubsection{New structure SGLC (SB)}

The maximum drift ratio of SB model in the EW direction is $0.88 \%$ and in the NS direction is $0.84 \%$. The drift ratio is less than $1 \%$ indicates that the SB model meets the requirements of SNI 1726-2012 (BSN, 2012) as a structure with risk category IV. Figure 33 and 
Figure 34 show the performance level of the SB model in EW direction and NS direction of the $1^{\text {st }} 3^{\text {rd }}$ floor is Operational $(\mathrm{OP})$ and floors $4^{\text {th }}-12^{\text {th }}$ is Immediate Occupancy (IO).

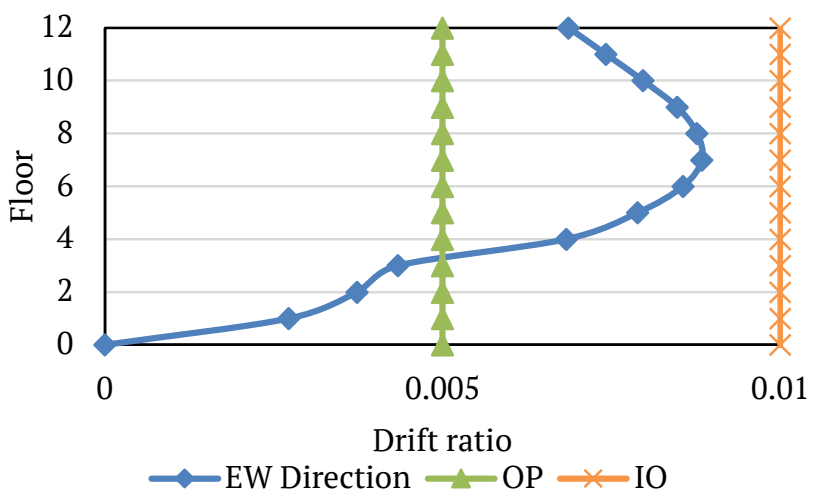

Figure 33. Drift ratio SB model on EW direction, El-Mayor earthquake.

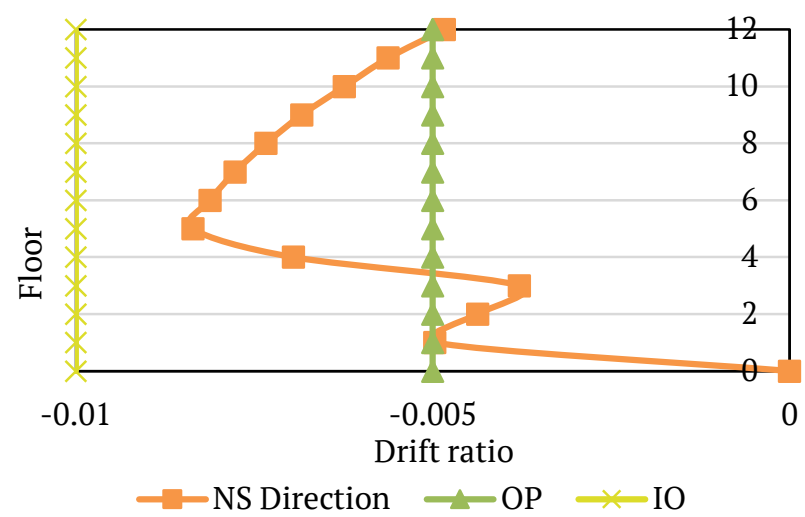

Figure 34. Drift ratio SB model on NS direction, El-Mayor earthquake.

\subsubsection{The composite structure of SGLC (SG)}

The maximum drift ratio of SKG model is $0.38 \%$ for $\mathrm{EW}$ direction and $0.44 \%$ for NS direction. The maximum drift ratio of SBG in the EW direction is $0.87 \%$ and in the NS direction is $0.77 \%$. Figure 35 and Figure 36 show the performance level of the SKG model in the EW and NS direction of the $1^{\text {st }} 3^{\text {rd }}$ floor is Operational (OP).

Figure 37 and Figure 38 show the performance level of SBG model in the EW direction for $1^{\text {st }}-3^{\text {rd }}$ floors are Operational (OP), for $4^{\text {th }}-12^{\text {th }}$ floor are Immediate Occupancy (IO) and in the NS direction for $1^{\text {st }}-3^{\text {rd }}$ floors and $12^{\text {th }}$ floor are Operational $(\mathrm{OP})$ and for $4^{\text {th }}-11^{\text {th }}$ floors are Immediate Occupancy (IO).

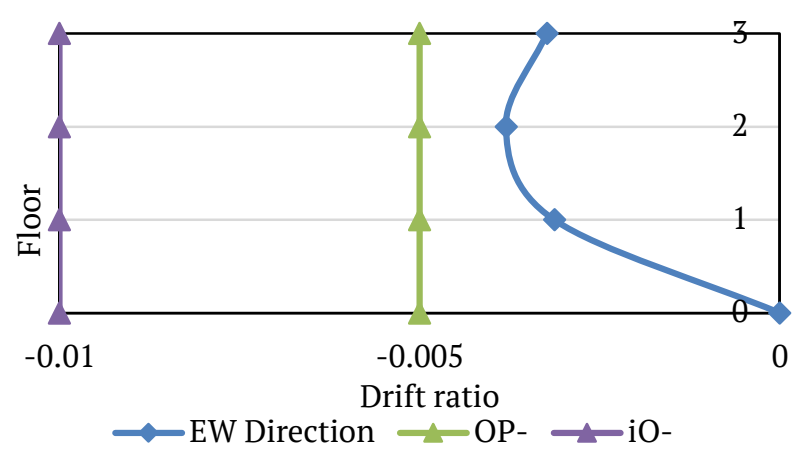

Figure 35. Drift ratio SKG model in EW direction, El-Mayor earthquake.

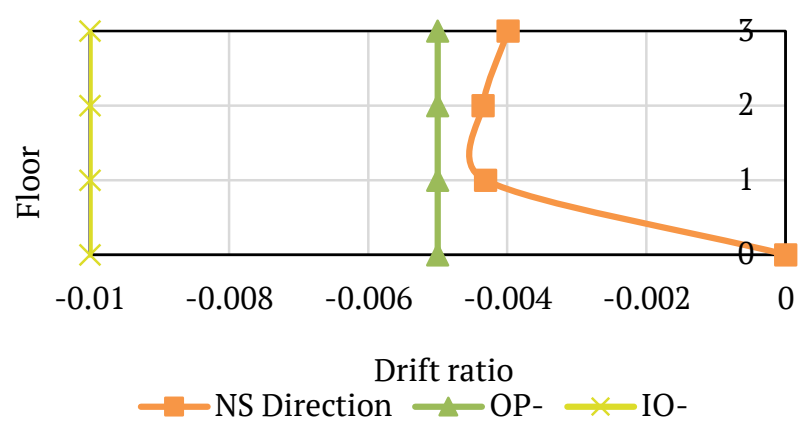

Figure 36. Drift ratio SKG model in NS direction, El-Mayor earthquake.

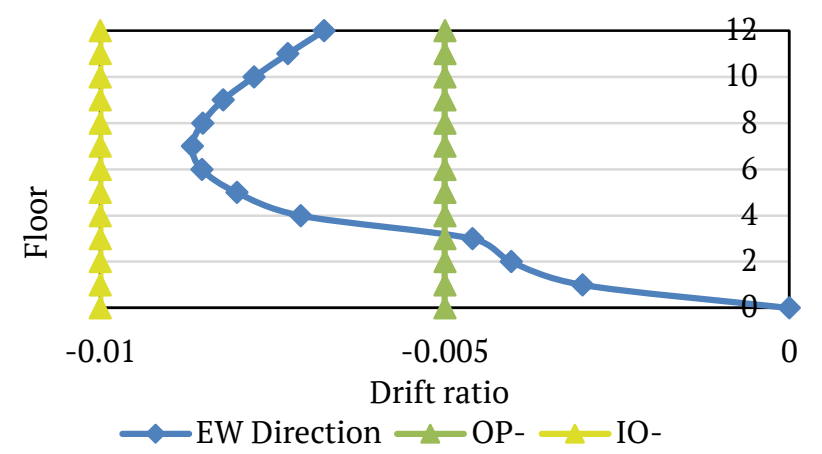

Figure 37. Drift ratio SBG model EW direction, El-Mayor earthquake.

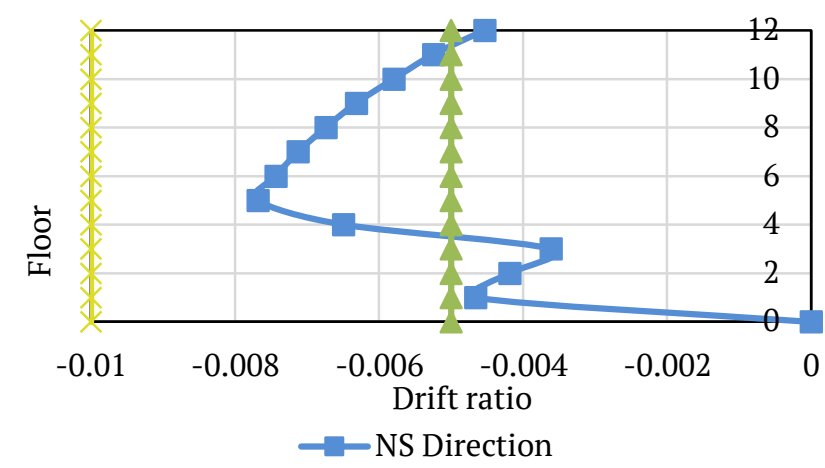

Figure 38. Drift ratio SBG model NS direction, El-Mayor earthquake. 


\subsubsection{Comparison of drift ratio structures before and after pounding}

The drift ratio of SKTD model is greater than the SKG model. After the structure is combined with the SB model, the drift ratio of SKG model decreases. The reduced of drift ratio is due to the deflection that occurs in the SKG model that is restrained by the structure of the SBG that is built nearby. Comparison of SKTD and SKG drift ratio in EW direction and NS direction can be seen in Figure 39 and Figure 40, respectively.

Figure 41 and Figure 42 show a comparison of the drift ratio between SB and SBG models. The drift ratio that occurs in SB model is greater than SBG model. The greatest differences in drift ratio are on the $8^{\text {th }}$ floor.

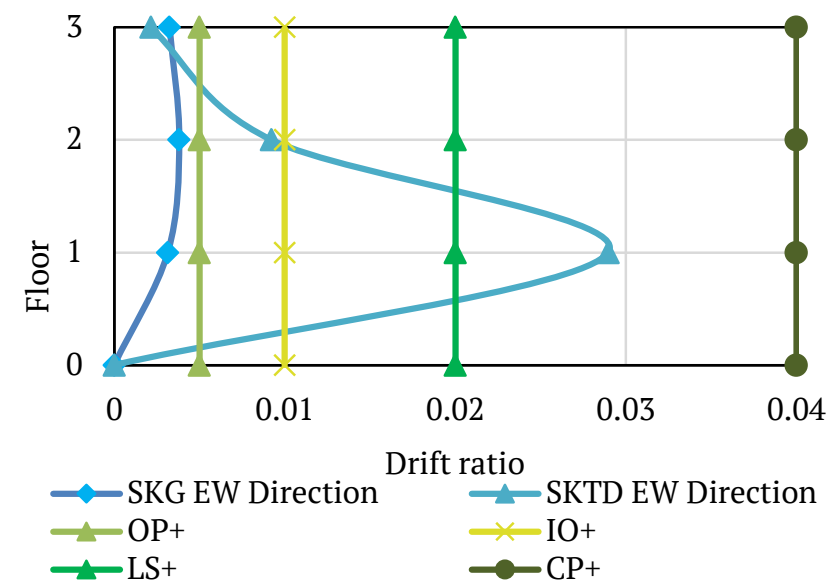

Figure 39. Comparison of SKTD and SKG drift ratio on EW direction.

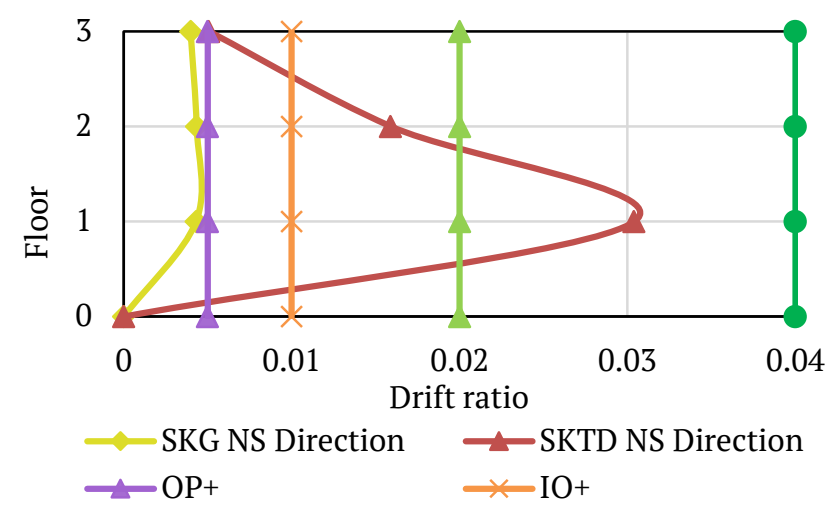

Figure 40. Comparison of SKTD and SKG drift ratio on NS direction.

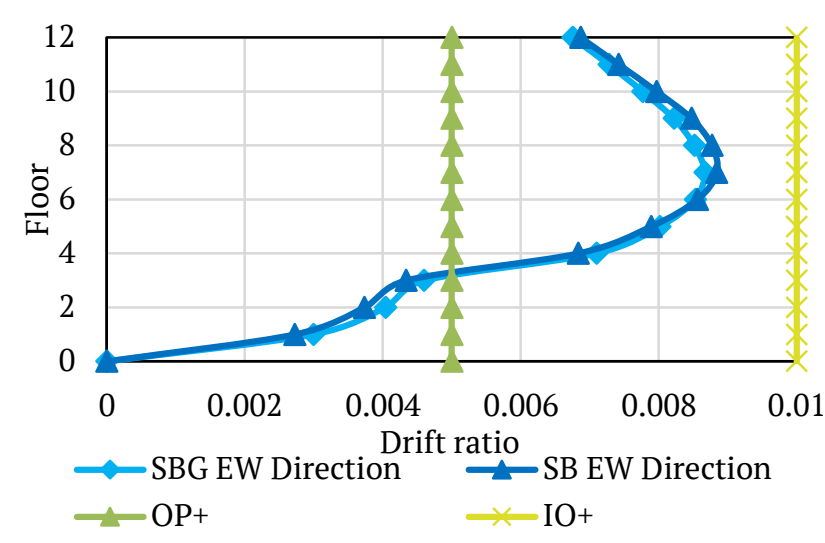

Figure 41. Comparison of SB and SBG drift ratio on EW direction.

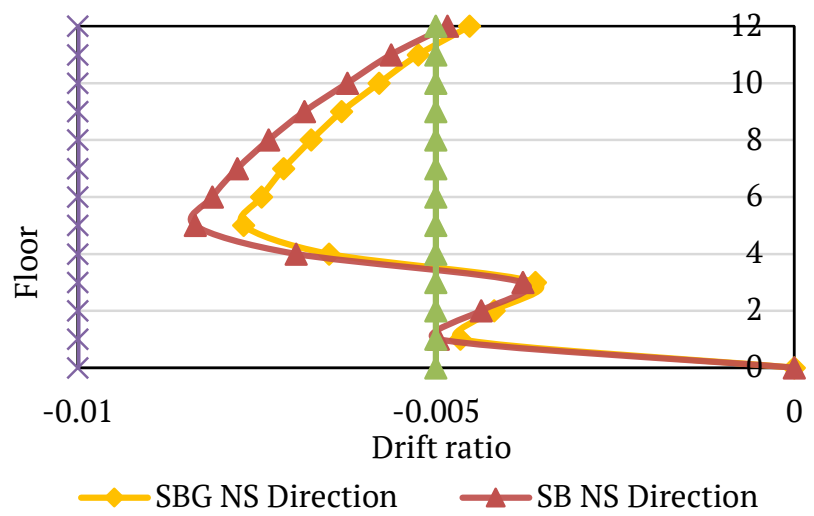

Figure 42. Comparison of SB and SBG drift ratio on NS direction.

\section{CONCLUSIONS}

Based on the results obtained performance evaluation conducted following several conclusions:

a) The KPFT building has a drift ratio of more than $1 \%$. Based on SNI 1726-2012 this building did not meet the requirements of the drift ratio for buildings with a risk category IV.

b) Based on FEMA 356 (2000), the performance level of the KPFT building on the $1^{\text {st }}$ floor is Collapse Prevention (CP), $2^{\text {nd }}$ floor is Life Safety (LS), and the $3^{\text {rd }}$ floor is Operational (OP).

c) The drift ratio of a new structure (SB) is less than $1 \%$. Based on SNI 1726-2012 this building qualifies for buildings with a risk category IV.

d) Based on FEMA 356 (2000), the performance level of the new structure on the $1^{\text {st }}-3^{\text {rd }}$ are Operational (OP) and $4^{\text {th }}-12^{\text {th }}$ are Immediate Occupancy (IO).

e) Composite structure (SG) has a drift ratio of less than 1\%. Based on SNI 1726-2012 this building meets the requirements of the drift ratio for buildings with a risk category IV 
f) The KPFT structure after pounding (SKG) has a smaller shear force value when compared to the structure without pounding. The new structure after pounding (SBG) has a greater shear force than a new structure without pounding.

g) The drift ratio of KPFT structure after pounding is reduced and the value is smaller than $1 \%$. Based on ISO 1726-2012, this structure has been qualified for buildings with a risk category IV.

h) The adding of a new structure near the KPFT structure is able to increase the performance level of that structure.

i) The drift ratio for a new structure on the floor that interacting with KPFT structure has increased but still fulfill the requirement of SNI 1726-2012.

\section{REFERENCES}

Akhsan, A. Y., 2014. Evaluasi Kinerja Gedung Kantor Pusat Fakultas Teknik (KPFT) Universitas Gadjah Mada Terhadap Pengaruh Gempa Dengan Analisis Pushover [Evaluation of KPFT Building Performance of Universitas Gadjah Mada towards Earthquake by Pushover Analysis], Yogyakarta: Universitas Gadjah Mada.

ASCE, 2000. FEMA 356 - Prestandard and Commentary for The Seismic Rehabilitation of Buildings, Washington, D. C.: Federal Emergency Management Agency.
BSN, 2012. SNI 1726-2012 Standar Perencanaan Ketahanan Gempa Untuk Struktur Bangunan Gedung, Jakarta: Badan Standarisasi Nasional (BSN).

BSN, 2013. SNI 03-2847-2002 Tata Cara Perhitungan Struktur Beton untuk Bangunan Gedung, Jakarta: Badan Standarisasi Nasional (BSN).

Jamal, A. U., 2009. Karakteristik Dinamik Gedung KPTU Fakultas Teknik UGM dengan Manggunakan Seismometer, Yogyakarta: Universitas Gadjah Mada.

Maison, B. F. \& Kasai, K., 1990. Analysis for Type of Structural Pounding. Journal of Structural Engineering, Volume 116, pp. 957-977.

Rojas, F. R., 2012. Pounding of an 18-Story Building during Recorded Earthquakes. Journal of Structural Engineering, Volume 138, pp. 1530-1544.

Sandra, D., 2007. Analisis Ulang Struktur Gedung KPFT FT UGM Terhadap Beban Gempa, Yogyakarta: Universitas Gadjah Mada. 
[This page is intentionally left blank] 